\title{
CONCENTRAÇÃO ESPACIAL DOS CRIMES VIOLENTOS CONTRA AS MULHERES NO MUNICÍPIO DE SÃO LUÍS, MA
}

\author{
Yata Anderson Gonzaga Masullo \\ Instituto Maranhense de Estudos Socioeconômicos e Cartográficos - IMESC \\ yanderson3@hotmail.com \\ Janderson Rocha Silva \\ Instituto Maranhense de Estudos Socioeconômicos e Cartográficos - IMESC \\ ir meta@hotmail.com \\ Izani Gonçalves dos Santos \\ Instituto Maranhense de Estudos Socioeconômicos e Cartográficos - IMESC \\ izani.gds@gmail.com \\ Silas Nogueira Melo \\ Universidade Estadual do Maranhão - UEMA \\ parasilas@gmail.com
}

\begin{abstract}
RESUMO
A violência contra a mulher se destaca por estar ligada a fatores históricos. Isso se expressa negativamente de forma heterogênea, tanto quanto à sua dinâmica territorial como temporal. Sob essa perspectiva o presente estudo analisa o nível de concentração espacial e temporal das ocorrências de crimes violentos contra as mulheres em São Luís MA. Para tanto, aplicou-se o método de análise exploratória espacial e o Indicador Local de Associação Espacial - LISA. Como resultado, foi possível verificar que entre 2014 e 2018, a capital maranhense registrou em $5 \%$ dos bairros, $43,1 \%$ das ocorrências de crimes violentos não letais e $83,3 \%$ de crimes violentos letais intencionais. Considerando os padrões e concentração dos crimes identificados com alta prevalência de violência contra mulheres, deve-se refletir sobre o desenvolvimento e o redirecionamento de políticas públicas específicas, com a finalidade de ampliar os canais de acesso à informação, de denúncias e principalmente de atendimento as mulheres vítimas de violência.
\end{abstract}

Palavras-chave: Crimes Violentos. Mulheres. São Luís.

\section{SPACE CONCENTRATION OF VIOLENT CRIMES AGAINST WOMEN IN THE CITY OF SÃO LUÍS, MA}

\begin{abstract}
Violence against women stands out for being linked to historical factors. This is expressed negatively in a heterogeneous way, both in terms of its territorial and temporal dynamics From this perspective, the present study analyzes the level of spatial and temporal concentration of the occurrences of violent crimes against women in São Luís - MA. For that, the method of spatial exploratory analysis and the Local Indicator of Spatial Association - LISA were applied. As a result, it was possible to verify that between 2014 and 2018, the capital of Maranhão registered in $5 \%$ of the neighborhoods, $43.1 \%$ of the occurrences of non-lethal violent crimes and $83.3 \%$ of intentional lethal violent crimes. Considering the patterns and concentration of crimes identified with a high prevalence of violence against women, it is necessary to reflect on the development and redirection of specific public policies, with the purpose of expanding the channels of access to information, denunciations and especially to deal with women victims of violence
\end{abstract}

Keywords: Violent Crimes. Women. São Luís. 


\section{INTRODUÇÃO}

A violência no Brasil, se apresenta de forma heterogênea, tanto quanto à sua dinâmica territorial como temporal. O crescimento da criminalidade e principalmente dos crimes violentos nas últimas décadas no País, tornou inegável a importância de estudos ligados ao planejamento e gestão com base em critérios, padrões, indicadores sociais e evidências que forneçam subsídios para a proposição de estratégias que atendam às demandas da sociedade.

Conforme o IPEA (2019), o Brasil registrou 57.341 mortes violentas intencionais, alcançando uma taxa de 27,5 por 100 mil habitantes, no ano de 2019. Em meio a esse contexto evidenciado, ressaltase que as ocorrências criminais supracitadas, são resultado de ações sociais que ocorrem no território, as quais se reproduzem geometricamente, influenciando de forma transversal setores e estruturas ligadas à saúde, educação e lazer. Isso demonstra como o território é indissociável (RAFFESTIN, 1993), e principalmente como as relações sociais interagem e se conectam dialeticamente (LEFEBVRE, 1999). É nesse contexto que Santos (2004) afirma que, para se compreender os fenômenos espaciais, faz-se necessário considerar o espaço em sua totalidade, a partir das funções, estruturas e processos históricos.

Desse modo, reconhecemos, com base em estudos como Weisburd et al (2012); Jones e Pridemore (2016); Hewitt et al. (2018); IMESC (2018) e Melo et al. (2019), como é imperativo alinhar as bases teóricas metodológicas da geografia com as técnicas de geoprocessamento e estatísticas, visando fornecer subsídios para a proposição de políticas públicas de prevenção, controle e enfretamento ao crime e aos mais diferentes tipos de violência.

Especificamente, a violência contra a mulher se destaca por estar ligada a fatores históricos, onde a mulher é vista como sujeito inferior ao homem e isso se expressa negativamente de diferentes formas, seja por meio de danos físicos, sexuais ou psicológicos. Um estudo conduzido pelo IPEA (2019) estimou que $88,8 \%$ dos casos de violência física e/ou sexual contra as mulheres foram cometidos por parceiros íntimos, no ano de 2018. Segundo o mesmo estudo, ocorreram 263.067 casos de lesão corporal contra mulheres, 1.206 feminicídios e 66.041 casos de violência sexual, ou seja, a cada 2 minutos ocorre um registro de violência doméstica no Brasil, com uma média de 180 estupros por dia e, em mais de $80 \%$ dos casos, as mulheres aparecem como vítimas.

Considerando as perspectivas apresentadas e que aproximadamente $70 \%$ das ocorrências registradas ocorrem nas cidades (LIRA, 2014), estudar o território urbano passa a ser vital para compreender como a violência influencia a construção, composição e organização espacial destes espaços. Nesse contexto, o presente estudo analisa a forma e o nível de concentração espacial e temporal das ocorrências dos crimes violentos contra as mulheres em São Luís. Localizado no Maranhão, a capital maranhense, registra uma taxa elevada de ocorrências (IMESC, 2020; MASULLO et al., 2019).

Inicialmente, o presente estudo descreve os procedimentos metodológicos utilizados para o desenvolvimento da pesquisa e, em seguida, apresenta-se um panorama da violência acometida contra as mulheres, através da comparação entre as realidades brasileira e maranhense. Posteriormente, analisa-se a dinâmica espacial dos crimes violentos letais intencionais - CVLI e crimes violentos não letais intencionais - CVNLI, com vítimas mulheres na capital maranhense entre 2014 e 2018. Insta afirmar que os resultados obtidos, apresentam mesmo que indiretamente, informações sobre a efetividade de políticas públicas realizadas no Estado.

\section{MATERIAL E MÉTODOS}

Considerando, as abordagens metodológicas aplicadas por Weisburd et al., (2012), Melo et al. (2015), Jones e Pridemore (2016), Chainey e Monteiro (2019). De acordo com os referidos estudos, os crimes apresentam dinâmica espacial concentrada e relativamente estável ao longo do tempo, variando o padrão das ocorrências conforme o tipo do crime e o uso da terra.

Para abordar os aspectos da concentração dos crimes violentos com vítimas mulheres no Maranhão e de forma específica em São Luís (Figura 01), e sua estabilidade espacial ao longo do tempo, adaptaram-se os procedimentos metodológicos, divididos em etapa 1 (Coleta e Tratamento dos Dados) e etapa 2 (Análise Espacial). 
Figura 01 - Mapa de delimitação dos bairros do município de São Luís (MA).

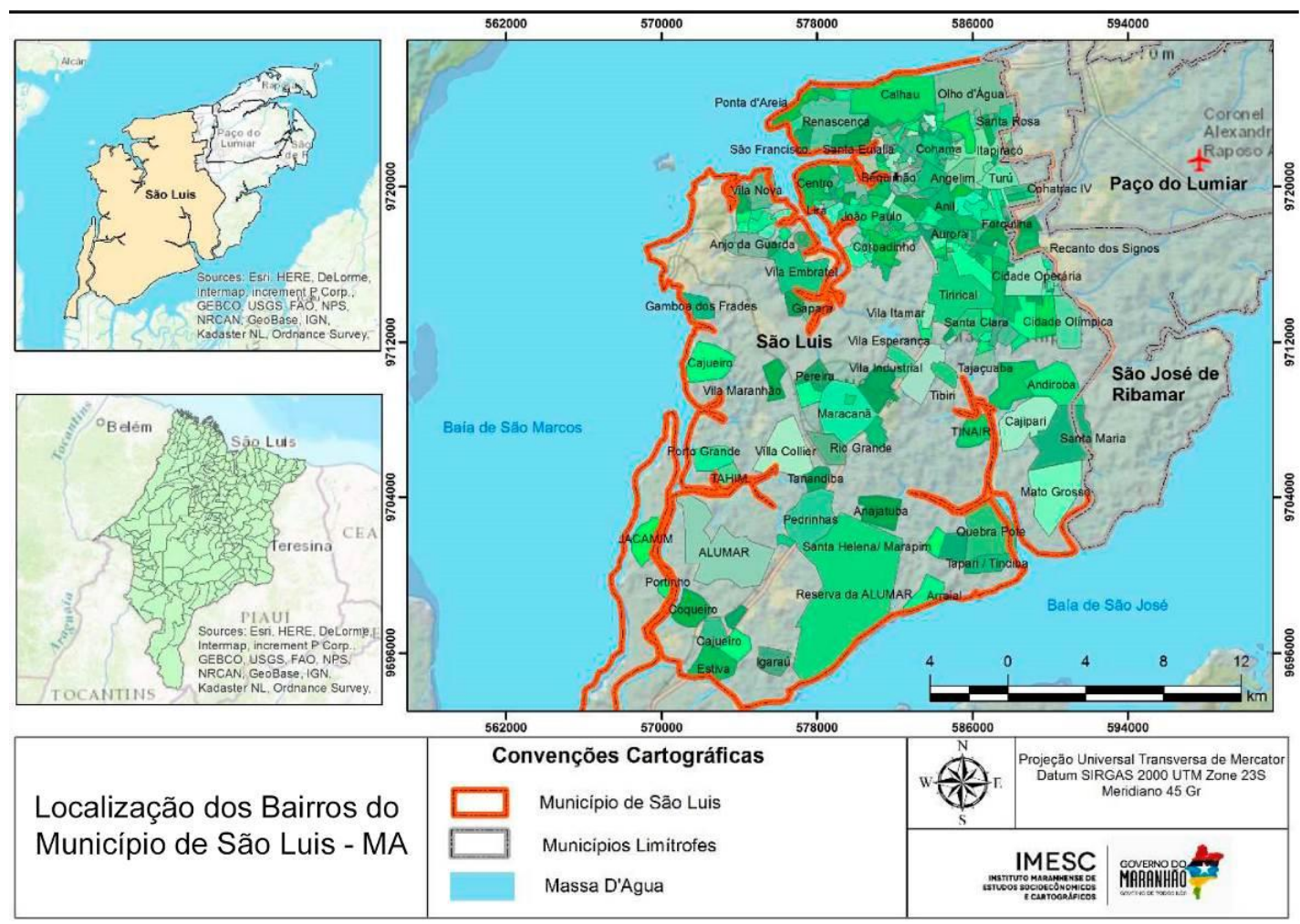

\section{ETAPA 1- COLETA E TRATAMENTO DOS DADOS}

Os dados referentes a CVLI e CVNLI foram obtidos por meio da Secretaria de Estado de Segurança Pública - SSP, correspondendo a série histórica de 2014 a 2018. A sigla CVLI foi criada em 2006 pela Secretaria Nacional de Segurança Pública (SENASP), vinculada ao Ministério da Justiça (MJ). Essa sintetização dos dados de violência é composta por homicídio doloso, lesão corporal seguida de morte, roubo seguido de morte ("latrocínio"). Ressalta-se, que de forma específica para o estudo, contabilizou-se os registros de feminicídio ${ }^{1}$. Referente os casos de CVNLI, agrupa-se, as ocorrências de roubo, lesão corporal e estupro, conforme o Ministério Público Estadual.

Após a coleta, seleção e tratamento das ocorrências dos crimes violentos em planilha Excel, calculouse a taxa de incidência em escala municipal e bairros de São Luís (MA). Para tanto, utilizou-se os dados populacionais por setor censitário, fornecidos pelo Instituto Brasileiro de Geografia e Estatística - IBGE (2010). Ressalta-se que a forma de tratamento estabelecida, possibilita a mensuração e comparação das ocorrências de CVLI e CVNLI, em áreas com diferentes estratos populacionais, seguindo a série histórica em estudo.

$$
\begin{gathered}
\text { Incidência }(\text { bairro })=\frac{N^{\circ} \text { de novas ocorrências }}{\text { Quantitativo populacional }} \times 10.000 \\
\text { Incidência (município) }=\frac{N^{\circ} \text { de novas ocorrências }}{\text { Quantitativo populacional }} \times 100.000
\end{gathered}
$$

Em seguida, o banco de dados dos crimes violentos com vítimas mulheres foi agrupado e transformado em formato SHAPEFILE, para posterior geocodificação dos endereços das ocorrências por meio do software Arc Gis 10.8. Esse procedimento, exigiu incialmente a consolidação da base cartográfica, haja vista a inexistência de legislação que defina os limites dos bairros da capital

${ }^{1}$ Lei no 13.104 , de 09 de março de 2015

$\begin{array}{lllll}\text { Caminhos de Geografia } \quad \text { Uberlândia-MG } & \text { v. 21, n. } 77 & \text { Out/2020 } & \text { p. 133-150 Página } 135\end{array}$


maranhense, bem como a utilização de diferente toponímia dos bairros por parte das instituições, tanto estaduais quanto municipais.

De acordo com a escala de análise, foram utilizados como base cartográfica:

- Município - utilizou-se a base fornecida pelo IBGE/IMESC;

- Delimitação e lista de Bairros - utilizou-se a base fornecida pelo INCID, por ser a delimitação oficial do município de São Luís.

Considerando, os problemas no endereçamento que impedem a localização dos casos notificados de CVLI e CVNLI, optou-se por aplicar as análises estatísticas com a unidade territorial em nível de bairro na capital maranhense.

Para a confecção dos mapas temáticos, foram utilizados os softwares ArcGIS 10.8 e QGIS 3.10. Isso possibilitou o alinhamento da base cartográfica, construção de análises espaciais e estatísticas. Como resultado, estruturou-se o geodatabase com base no conjunto de dados vetorial.

\section{ETAPA 2 - ANÁLISE ESPACIAL}

A sintetização e tratamento dos dados permitiu a aplicação da metodologia em diferentes escalas intra-urbana (município e bairro), bem como serviu de base de referência, comparação e nível de associação espacial para se estabelecer uma abordagem conceitual, que considera a conexão entre os diversos níveis e parâmetros técnicos utilizados para a análise espacial. Como suporte, utilizou-se o método de análise exploratória espacial, conforme Câmara et al. (2004).

Como exposto, a partir das limitações da base de dados utilizada, a análise espacial foi desenvolvida em nível municipal e bairro. No primeiro momento, avaliou-se o nível de concentração dos registros de CVLI e CVNLI com vítimas mulheres em escala municipal e em nível de bairros para São Luís (0 $100 \%$ ), em seguida, utilizou-se o espectro de concentração das ocorrências entre $25 \%$ e $50 \%$ dos bairros. Esse procedimento de análise, foi consolidado a partir da espacialização dos registros de CVLI e CVNLI, com os endereços fornecidos pela SSP. Dessa forma foi possível a geração de Kernel e mapas de densidade, para estabelecer a complementaridade dos eventos e a análise globalizada da dimensão espaço-temporal do risco à violência.

Em relação aos dados de incidência dos registros de CVLI e CVNLI por bairro, aplicou-se o Indicador Local de Associação Espacial - LISA², proposto por Anselin (1995). A aplicação deste método, objetivou identificar agrupamentos espaciais com valores de atributos semelhantes (clusters), objetos anômalos, ou seja, situações atípicas (outliers).

O LISA pode ser representado pelo cálculo:

$$
I_{i}=\frac{z_{i} \sum_{j=1}^{n} w_{i j} z_{j}}{\sum_{j=1}^{n} w_{j}^{2}}
$$

Fonte: Anselin (1995).

A interpretação mais direta do LISA, foi utilizada para sistematizar os casos de CVLI e CVNLI, com vítimas mulheres entre 2014 e 2018. Infere-se a aplicação dessa técnica, a quantificação da influência de cada bairro com os seus respectivos vizinhos, identificando autocorrelação espacial com base nas características geográficas e o grau de associação espacial entre o conjunto de dados (ROGERSON, 2012).

A autocorrelação, baseada na localização e nos valores de cada área (LENTZ, 2009) mensurada pelo LISA, permitiu avaliar se o padrão de distribuição é:

\footnotetext{
${ }^{2}$ Segundo Anselin (2000), o LISA visa: a) identificar padrões de associação espacial significativos; b) decompor o índice global de associação espacial.

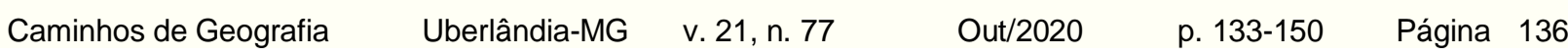


1. HH: alta-alta (agrupamento de valores altos e próximos);

2. LL: baixa-baixa (agrupamento de valores baixos e próximos);

3. HL: alta-baixa (outlier de valores altos que não se agrupam, pois se encontram em meio a valores baixos);

4. LH: baixa-alta (outlier de valores baixos que não se agrupam, pois se encontram em meio a valores altos);

5. Não significativos: não se enquadram nos agrupamentos, pois apresentam níveis variados assim como os valores dos vizinhos.

Os procedimentos técnicos aplicados, refletem a relação entre os elementos e os fenômenos espaciais, considerando a existência de dependência entre as variáveis utilizadas e a formação de múltiplos territórios em escala regional e intra-urbana.

\section{RESULTADOS E DISCUSSÃO CRIMES VIOLENTOS COM VÍTIMAS MULHERES: CONTEXTO BRASILEIRO E MARANHENSE}

Os crimes violentos contra as mulheres, têm apresentado tendência de crescimento na última década (IPEA, 2017). A violência contra a mulher, está ligada a fatores históricos, que qualificam a mulher como inferior ao homem. O estudo sobre a violência de gênero no Brasil, realizado por Cerqueira e Coelho (2014), indica que a ideologia do patriarcalismo e sua expressão machista dissemina de forma explícita a cultura do machismo em meios de comunicação e no Sistema de Justiça Criminal. O padrão de evolução dos crimes letais contra as mulheres no Brasil, segue diferentes direções entre as unidades federativas (IPEA, 2017).

Conforme Gráfico 01 a seguir, identifica-se aumento de $4 \%$ dos crimes letais contra mulheres entre 2015 e 2018, no Brasil. No mesmo período, verifica-se redução de 11,9\% dos casos de homicídios com vítimas mulheres, enquanto registra-se ampliação de $171 \%$ dos casos de feminicídio no País.

Gráfico 1 - Ocorrências de Homicídio e Feminicídio no Brasil entre 2015 e 2018.

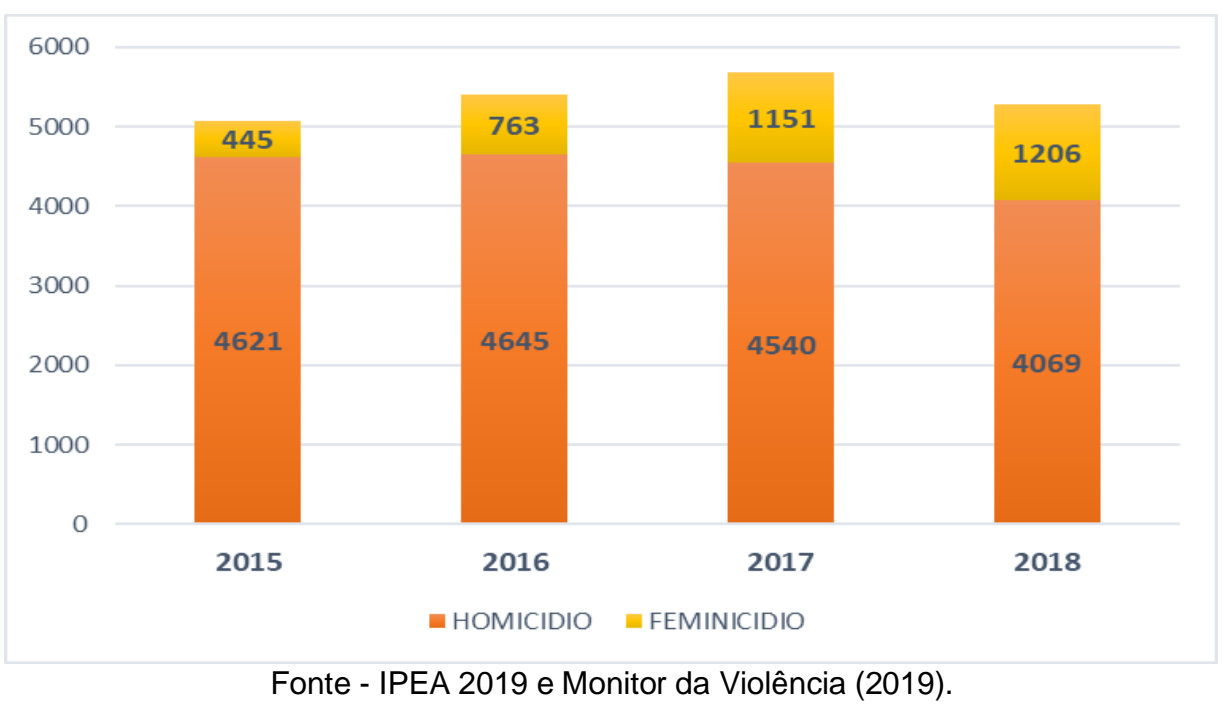

Conforme relatório do UNICEF (2017), entre os aspectos que solidificam esse cenário, estão justamente, os casos em que as mulheres não esboçam reações contrárias a situações de violência doméstica, seja por medo de represálias do violentador, ou mesmo pela humilhação diante da sociedade. Contudo, mesmo diante desse contexto, o estudo supracitado, ressalta que os homens são as principais vítimas de homicídios, por diversos motivos (consumo de álcool, drogas e o acesso a armas de fogo, maior tendência dos homens em participar de quadrilhas e atividades ligadas ao crime organizado). 
Yata Anderson Gonzaga Masullo

Janderson Rocha Silva

Concentração espacial dos crimes violentos contra as

mulheres no município de São Luís, MA

Izani Gonçalves dos Santos

Silas Nogueira Melo

Considerando a significativa variação regional dos crimes no Brasil, a seguir, apresenta-se a dinâmica espacial e temporal dos crimes violentos com vítimas mulheres no Maranhão (Figura 02 e Gráfico 02).

Figura 02 - Dinâmica espacial dos crimes violentos letais contra as mulheres no Maranhão, entre 2015 e 2018.

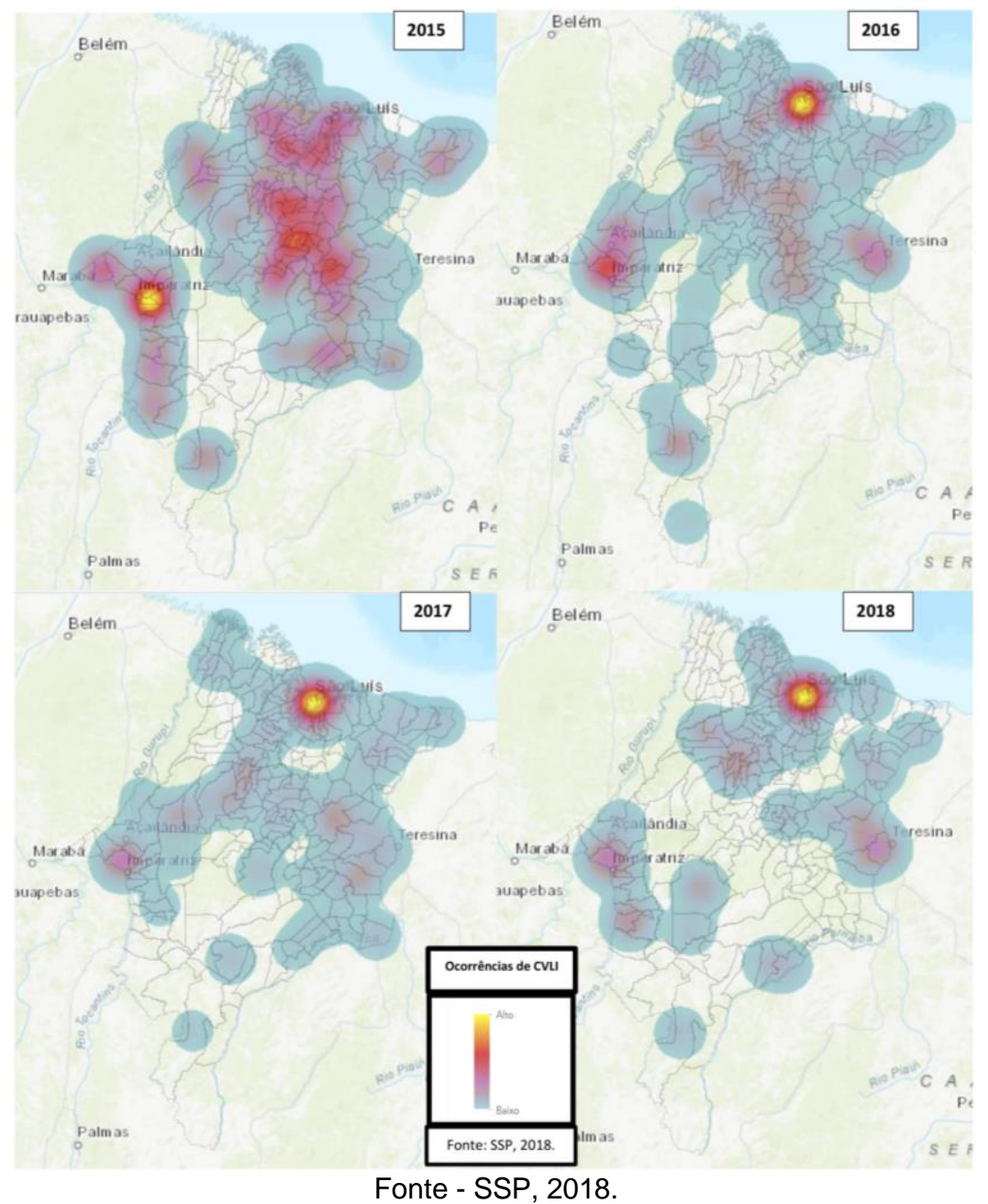

Gráfico 02 - Crimes violentos letais no Maranhão, entre 2015 e 2018.

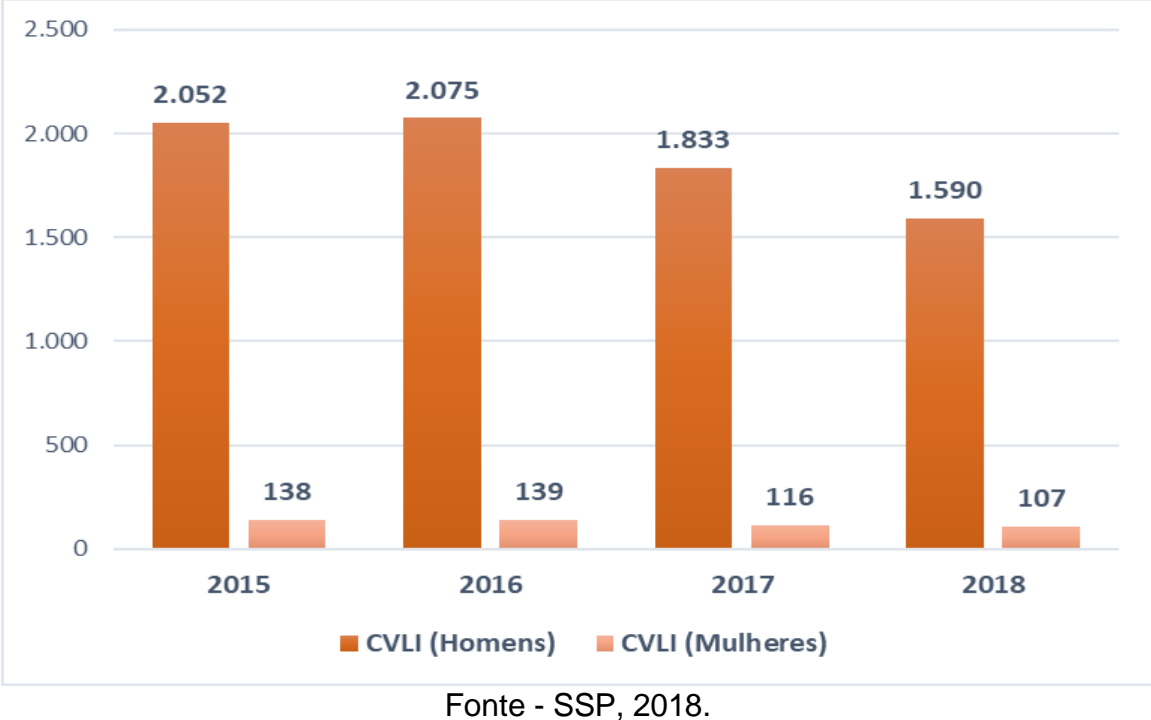

Fonte - SSP, 2018.

v. 21 , n. 77

Out/2020

p. $133-150$ 
Verifica-se na Figura 01, diminuição na dispersão das ocorrências de CVLI no Estado, com aumento da concentração nos municípios de São Luís, Imperatriz e São José de Ribamar. Esses municípios, centralizam 40,7\% dos registros de CVLI com vítimas mulheres, entre 2015 e 2018. Desse modo, observa-se que a dinâmica das ocorrências de CVLI no Maranhão até 2015, refletiu um movimento de espraiamento e interiorização do crime, o que deflagrou um movimento de concentração de casos, assim como Cerqueira et al. (2016), observa a dinâmica espacial da violência em escala nacional.

O perfil do sexo feminino vítima de crimes letais revela a maior vulnerabilidade das mulheres negras $(61 \%)$, sendo que $70,7 \%$ das vítimas cursaram até o ensino fundamental, enquanto $7,3 \%$ tem ensino superior e $58 \%$ possuem entre 20 e 39 anos. Ao mesmo tempo, os registros demonstram que em $51 \%$ dos casos existe uma relação do autor com as mulheres (IPEA, 2019).

Faz-se necessário frisar que a violência contra a mulher, representa uma grave violação aos direitos humanos, bem como a igualdade entre homens e mulheres trazidas pela Constituição Federal de 1988, conforme o art. 5o-, inciso I. Esse tipo de violência, pode se apresentar de diversas formas, como, por exemplo na modalidade de violência doméstica e familiar contra a mulher, lesão corporal, no crime de feminicídio ou nos crimes sexuais (ROSA, 2017).

Entre os crimes não letais perpetrados contra as mulheres, destaca-se o estupro, por possuir grande subnotificação, como afirma a Pesquisa Nacional de Vitimização produzida pelo CRISP (2013). O estudo citado verificou que, no Brasil, somente $7,5 \%$ das vítimas de violência sexual registram o crime nas delegacias. Realidades como essas, são vistas em diferentes países do mundo, como demonstra o Instituto de Criminologia Australiano, em estudo intitulado The women's safety survey. De acordo com a pesquisa, somente $15 \%$ das vítimas de violência sexual australianas, reportam ocorrência de estupro a polícia. No Canadá estima-se que aproximadamente $88 \%$ das agressões sexuais sofridas pelos canadenses maiores de 15 anos não são relatados à polícia (HEWITT et al., 2018). No Brasil, estudos apontam que muitas vítimas procuram ajuda hospitalar mas não denunciam os ofensores (MELO et al., 2019) e que a decisão de não reportar os crimes também possui uma associação espacial (MELO et al., 2020).

Para Saffioti (2015, p. 75), "a desigualdade, longe de ser natural é posta pela tradição cultural, pelas estruturas de poder, pelos agentes envolvidos na trama das relações sociais". Sob essa perspectiva, observa-se que os índices de violência contra a mulher permanecem elevados, por exemplo, quando analisa-se a violência doméstica e familiar, resta claro que as mulheres ainda são as principais vítimas, o que influencia diretamente a sua qualidade de vida (ROSA, 2017).

Considerando, o alto nível de concentração das ocorrências letais e não letais, o presente estudo segue analisando e caracterizando a dinâmica espacial e temporal dos crimes violentos com vítimas mulheres, de forma específica na capital maranhense. No entanto, é preciso compreender que a análise espacial a ser aplicada não deve se sustentar, apenas em teorias e métodos quantitativos, baseados na identificação dos padrões de elementos dispostos em mapas e definidos por coordenadas geográficas, como se refere Hagertrand (1966), nesta pesquisa buscamos integrar princípios como arranjo espacial ${ }^{3}$, processos de espaço-tempo ${ }^{4}$ e modelagem espacial ${ }^{5}$ conforme Ferreira (2014).

\section{DINÂMICA ESPACIAL DOS CRIMES VIOLENTOS LETAIS INTENCIONAIS CONTRA AS MULHERES EM SÃO LUÍS}

Em São Luís, cerca de $95,3 \%$ da incidência de CVLI foram contra o sexo masculino, enquanto somente 4,7\% foram registrados contra mulheres, entre 2014 e 2018 e, destas, 88,6\% foram vítimas de homicídio ou feminicídio. Nesse mesmo período, a capital maranhense seguiu a tendência estadual de diminuição dos registros de CVLI, apresentando redução de $43,5 \%$ da incidência (100 $\mathrm{mil} / \mathrm{hab}$ ) dessas ocorrências com vítimas mulheres (Gráfico ).

\footnotetext{
${ }^{3}$ Padrão locacional dos elementos (pontos, linhas e áreas) e sua configuração espacial.

${ }^{4}$ Alterações sofridas pelos arranjos espaciais em razão dos fluxos e influencias da interação espacial.

${ }^{5}$ Identifica e modela arranjos espaciais com base na construção de cenários baseados na dinâmica espacial e temporal dos fenômenos analisados. 
Yata Anderson Gonzaga Masullo

Janderson Rocha Silva

Concentração espacial dos crimes violentos contra as mulheres no município de São Luís, MA

Gráfico 3 - Incidência (por 100 mil habitantes) de CVLI com vítimas mulheres entre 2014 e 2018 em São Luís (MA).

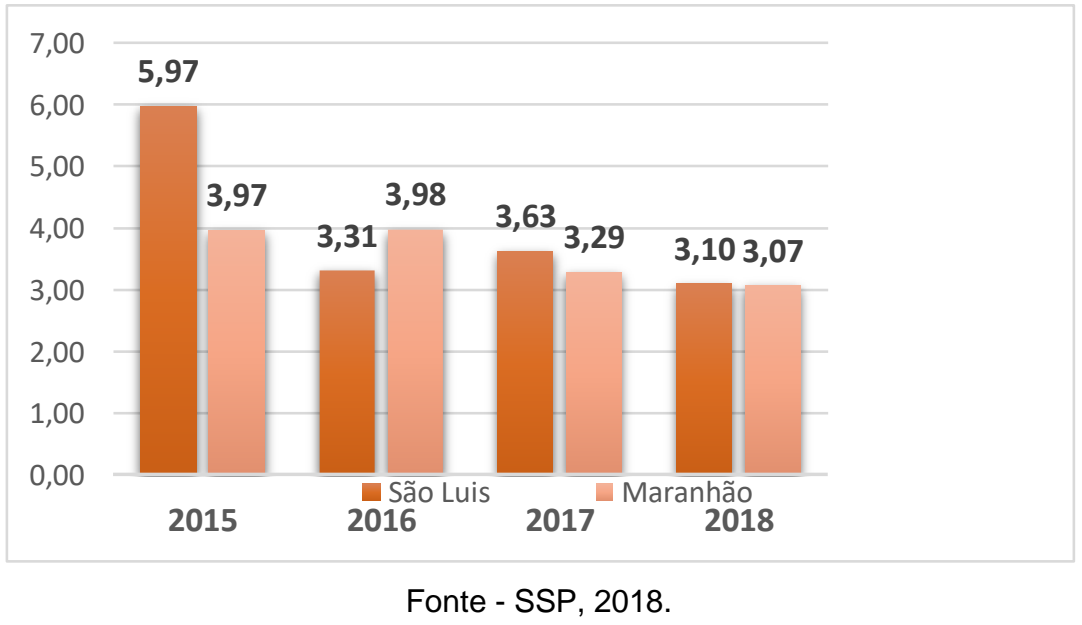

Destaca-se, nesse contexto de redução, as ações preventivas realizadas pelo Governo do Estado, como a criação da Patrulha Maria da Penha ${ }^{6}$. No que tange a dinâmica espacial e temporal dos casos de CVLI com vítimas mulheres entre 2014 e 2018 em São Luís, identificou-se um maior agrupamento dos casos na faixa central do município, com a formação de eixos de concentração e dispersão das ocorrências na área urbana e rural (Figura 03).

Figura 3 - Concentração de casos de CVLI com vítimas mulheres entre 2014 e 2018, São Luís/MA.

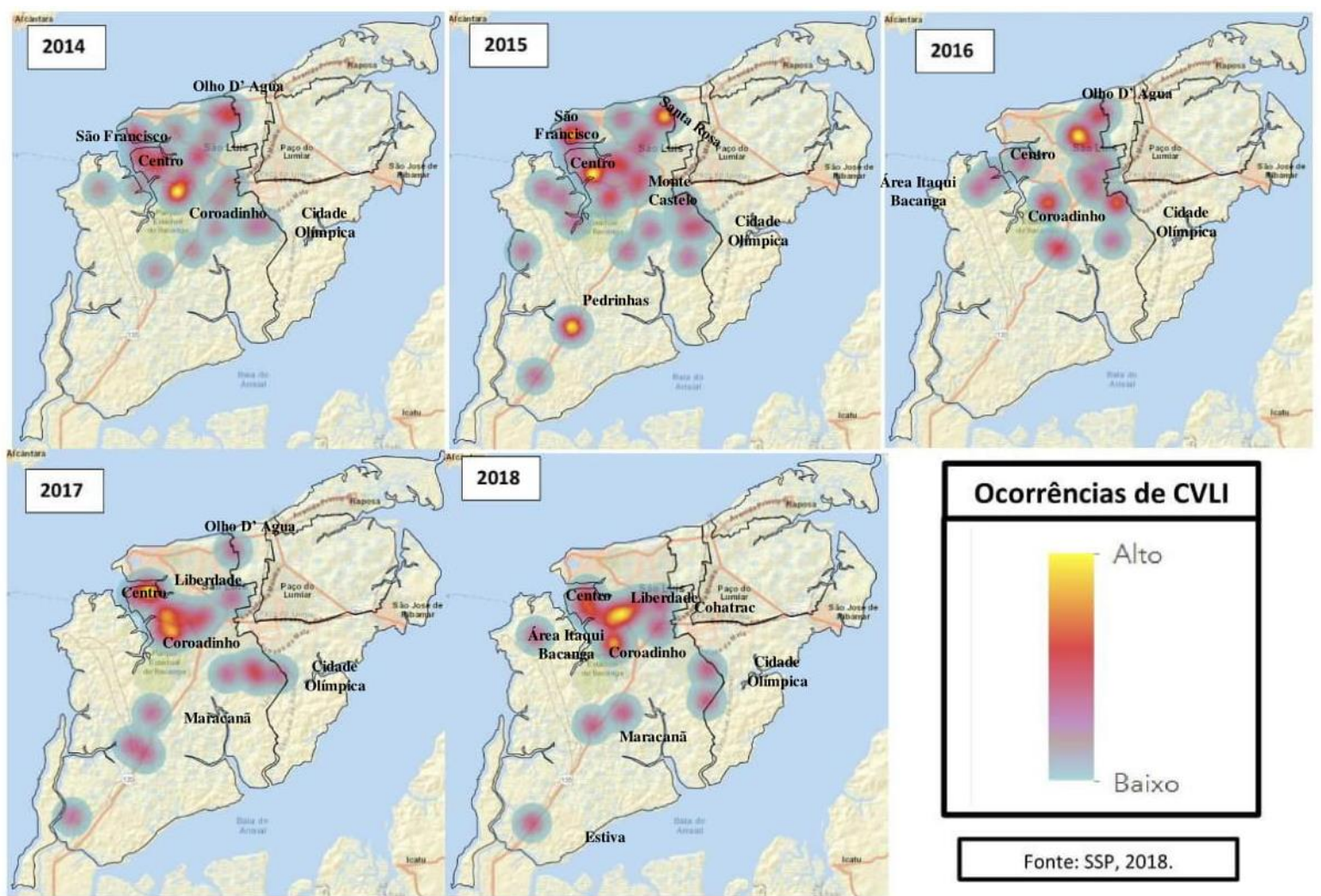

${ }^{6}$ A patrulha Maria da Penha criada através do decreto $31.763 / 2016$, conta com policiais militares treinados para acompanhar as denúncias de violação de medidas protetivas ou situações de ameaças iminentes. 
A Figura 3, apresenta significativa dispersão dos casos de CVLI na área urbana nos anos de $2014 \mathrm{e}$ 2015, com a maior concentração das ocorrências entre os bairros do Centro, Monte Castelo e Coroadinho, além de formar eixos na Cidade Olímpica, Olho D'Agua, Turu e Pedrinhas. A partir de 2016, verifica-se redução da centralização das ocorrências de CVLI com vítimas mulheres na faixa central da zona urbana, acompanhado por uma diminuição de 38,7\% dos casos entre 2014 e 2016.

Em 2017 e 2018, percebe-se prevalência dos casos de CVLI com vítimas mulheres nos bairros do Coroadinho, João Paulo, Liberdade e Cohab, além da dispersão das ocorrências em bairros da zona rural, como Rio Grande e Coqueiro. Observa-se, que os bairros com maior quantitativo de registros, estão localizados em áreas densamente habitadas, consideradas pelo IBGE como aglomerados subnormais $^{7}$ (invasões, palafitas e vilas) de alta pressão originária de intenso fluxo e concentração de pessoas. Assim como observado por Mustaine et al. (2014), verifica-se, que a grande densidade habitacional e o constante fluxo de pessoas, mesmo que de forma inicial, apresenta associação positiva com os crimes de gênero.

Identificou-se, que os registros de CVLI com vítimas mulheres, concentraram-se somente em 7,6\% dos bairros do município de São Luís. No período analisado, percebe-se que, com a redução sucessiva das ocorrências, amplia-se a concentração dos casos (Gráfico 4), mesmo com o registro das ocorrências em bairros que anteriormente não registravam esse tipo de violência. Isso, pode ser visualizado principalmente na zona rural do município.

Gráfico 4 - Percentual de concentração de CVLI em 5\% e 1\% dos bairros de São Luís (MA), entre 2014 e 2018.

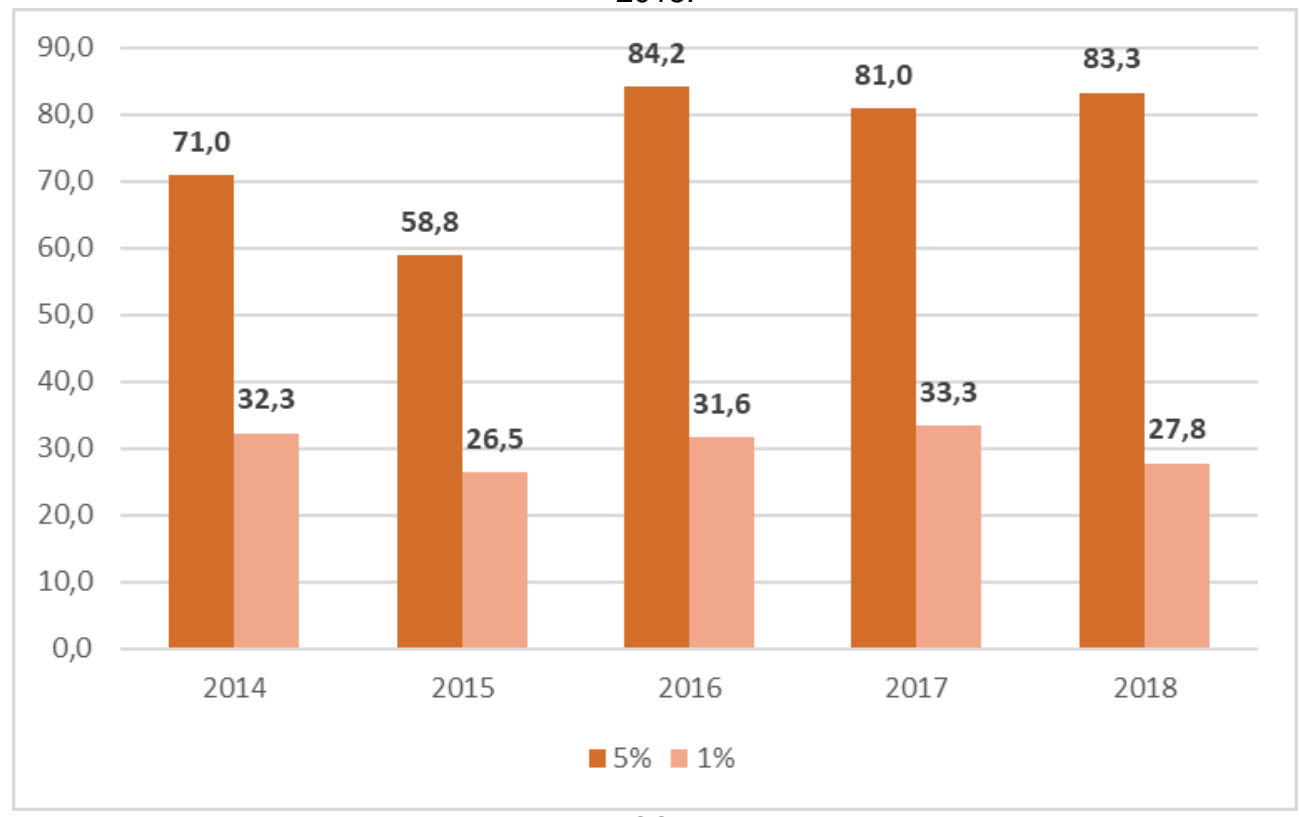

Fonte - SSP, 2018

No período analisado, em média $5 \%$ dos bairros de São Luís, concentram $75,6 \%$ dos casos de CVLI, enquanto que em $1 \%$ dos bairros ocorrem $30,3 \%$ dos casos. Observa-se, ampliação dos registros na faixa de $5 \%$ dos bairros de 13,3p.p entre 2014 e 2018, ao mesmo tempo, em que se identifica redução de 4,5p.p no espectro de $1 \%$ dos bairros. Isso, demonstra tanto a centralização quanto a dispersão dos casos registrados.

\footnotetext{
7 Considera-se um aglomerado um conjunto constituído de, no mínimo, 51 unidades habitacionais (barracos, casas...) carentes, em sua maioria de serviços públicos essenciais, ocupando ou tendo ocupado, até período recente, terreno de propriedade alheia (pública ou particular) e estando dispostas, em geral, de forma desordenada e densa (IBGE, 2011).
} 
A partir do contexto evidenciado, é preciso considerar as características específicas da violência contra mulheres. Esse tipo de violência, não é apenas uma manifestação da desigualdade de gênero, ele contribui para a manutenção do desequilíbrio de poder entre homens e mulheres (UNICEF, 2017). Especificamente em São Luís, aplica-se o LISA, com o objetivo de avaliar o comportamento espacial dos registros de CVLI com vítimas mulheres, em diferentes épocas do ano e a influência da sazonalidade na violência (Figura 4). A partir das ocorrências de CVLI por bairro, detecta-se a formação de diferentes clusters espaciais ${ }^{8}$, com significativa dinâmica espaço-temporal. Isso, pode ser observado na formação de um conjunto de bairros, caracterizando toda a região de estudo.

Figura 4 - Mapas de CVLI com vítimas mulheres (LISA) entre 2014 a 2018, São Luís/MA.

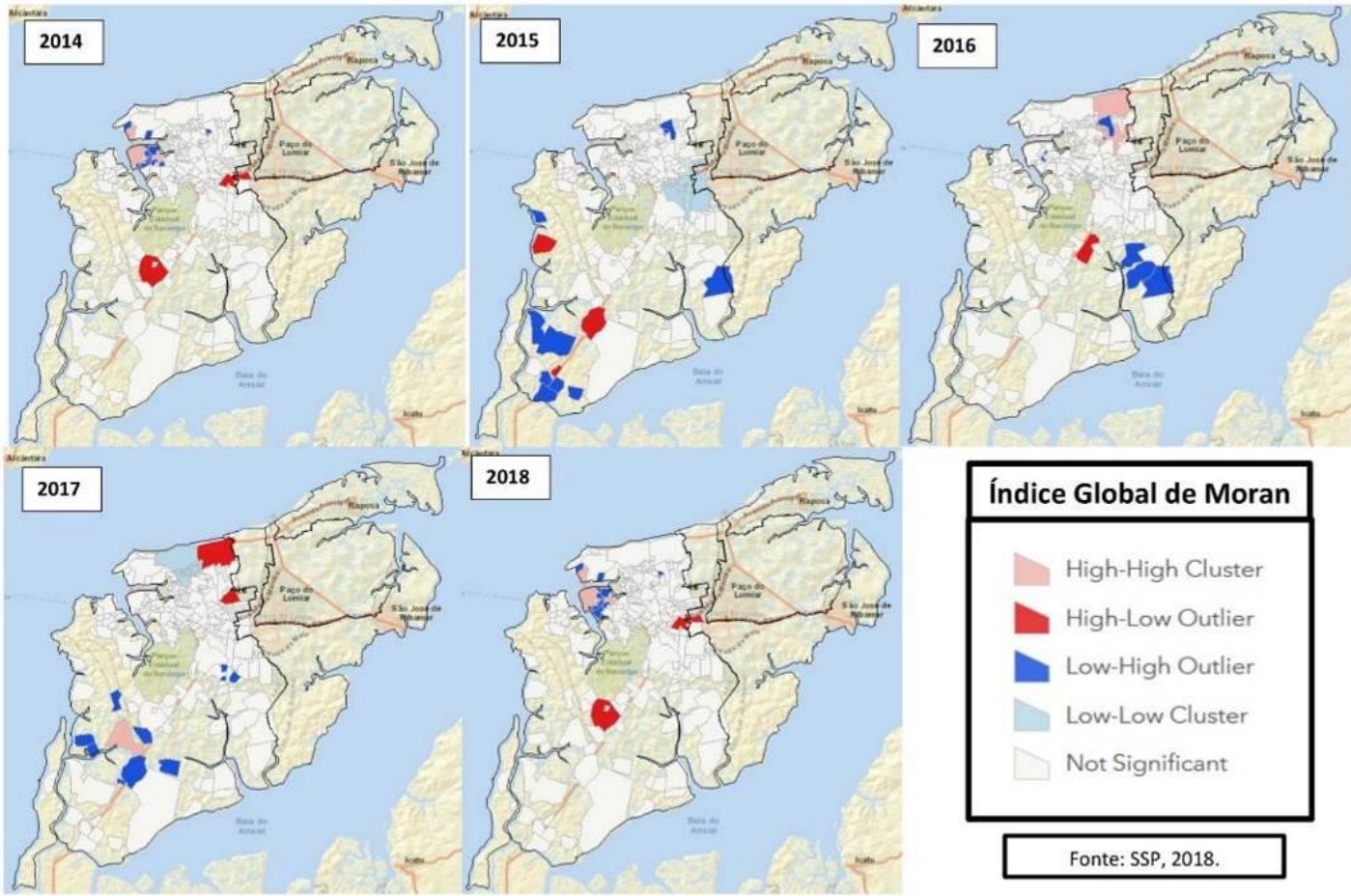

Em 2014, visualizam-se clusters HH (alta concentração de casos) entre os bairros do São Francisco, Centro e Monte Castelo. Tal correlação, demonstra áreas com alta incidência, cercados de outros bairros com altas proporções de CVLI. Ao mesmo tempo, identificam-se outliers HL (alta concentração de casos próximos a áreas com baixa incidência) na Forquilha e no Maracanã, além de LH (baixa concentração de casos próximos a áreas com alta incidência) com continuidade entre os bairros do Jaracaty, Camboa, Liberdade, Diamante, Vila Passos e Goiabal. Já a Ilhinha e o Recanto Fialho, também se apresentam como outlier LH, mas de forma isolada. Isso, evidencia bairros com baixa incidência, cercados por bairros com alta probabilidade de ocorrências de crimes letais contra mulheres.

No ano de 2015, verificam-se outliers LH (baixa concentração de casos próximos a áreas com alta incidência) na área urbana no Jardim Eldorado e Recanto Fialho, bem como em bairros como a Camboa dos Frades, Santa Maria, Vila Samara e Estiva, localizados na zona rural do município. Identifica-se, de forma isolada bairros com alta proporção, cercados por bairros com baixa incidência de CVLI com vítimas mulheres. Essa dinâmica, forma clusters HL (alta concentração de casos próximos a áreas com baixa incidência) entre os bairros do Inhaúma, Pedrinhas e Cajueiro Camboa. Registra-se, como outlier LL (baixa concentração de casos próximos a áreas com baixa incidência) os bairros da Cidade Operária, São Cristovão, Planalto Anil e Cohatrac.

8 Cluster espacial é um agregado de eventos no espaço ou a ocorrência de "taxas semelhantes" em área próximas (MELO e MATHIAS, 2010). 
Em 2016, observam-se clusters HH (alta concentração de casos) entre os bairros do Olho d'Água, Sant Rosa e Turú. Essa correlação, demonstra áreas com altas proporções do indicador, cercados de outros bairros com altas taxas de CVLI. Por outro lado, identifica-se de forma isolada no bairro Tibiri, alta proporção de CVLI, cercado por bairros com baixa incidência de CVLI com vítimas mulheres, formando clusters HL (alta concentração de casos próximos a áreas com baixa incidência). Em relação aos clusters LH (baixa concentração de casos próximos a áreas com alta incidência), verificase continuidade entre os bairros da Santa Maria, Tajaçuaba e Cajipari, o que evidencia bairros com alta incidência cercados por bairros com baixa incidência.

No ano de 2017, identifica-se na zona rural clusters $\mathrm{HH}$, entre os bairros da Vila Colier e Tanandiba, bem como outliers LH nos bairros do Rio Grande, Anajatuba, Porto Grande, Tahim e Vila Maranhão. Na zona urbana, observa-se a formação de clusters HH nos bairros do Olho d'Água e no Itapiracó, e LL no Calhau e Vinhais. Já em 2018, a formação dos clusters HH concentra-se entre o São Francisco, Centro e Monte Castelo, enquanto os outliers HL, estão situados entre os bairros da Forquilha e Maracanã e LH no Jaracaty, Camboa, Liberdade, Diamante, Vila Passos, Goiabal e Ilhinha.

O alto nível de concentração e a distribuição das ocorrências de CVLI, apresenta autocorrelação positiva entre os registros, indicando presença de dependência espacial global dos bairros próximos, com a formação de clusters na zona rural e urbana. Para Ceccato et al. (2017), contexto como o evidenciado, demonstra categoricamente como as características singulares de desorganização social influenciam esses tipos de crime, considerando que as desvantagens sociais (Weisburd et al., 2015) variam no território e estão fortemente relacionados ao crime no nível intra-urbano.

A dinâmica observada, mostra como é difícil compreender as diferentes expressões das violências baseadas em gênero, e traçar os caminhos institucionais para enfrenta-las. Nesse sentido, também é relevante pontuar as ocorrências de $\mathrm{CVNLI}$, que em muitos casos estão diretamente relacionadas aos registros dos crimes letais contra as mulheres.

\section{DINÂMICA ESPACIAL DOS CRIMES VIOLENTOS NÃO LETAIS INTENCIONAIS CONTRA AS MULHERES EM SÃO LUÍS}

Na capital maranhense, os Crimes Violentos Não Letais (CVNLI) que ocorreram no período de 2014 a 2018, subdividiram-se em: roubo (74,3\%), lesão corporal (24\%) e estupro $(1,7 \%)$, como indica o relatório Dinâmica Espacial dos Crimes Violentos no município de São Luís (IMESC, 2018). Ressaltase que entre 2014 e 2018, São Luís apresentou redução de 39\% da incidência (100 mil/hab) de CVNLI com vítimas mulheres (

Gráfico ).

Gráfico 5 - Incidência (por 100 mil habitantes) de CVNLI com vítimas mulheres entre 2014 e 2018 em São Luís (MA).

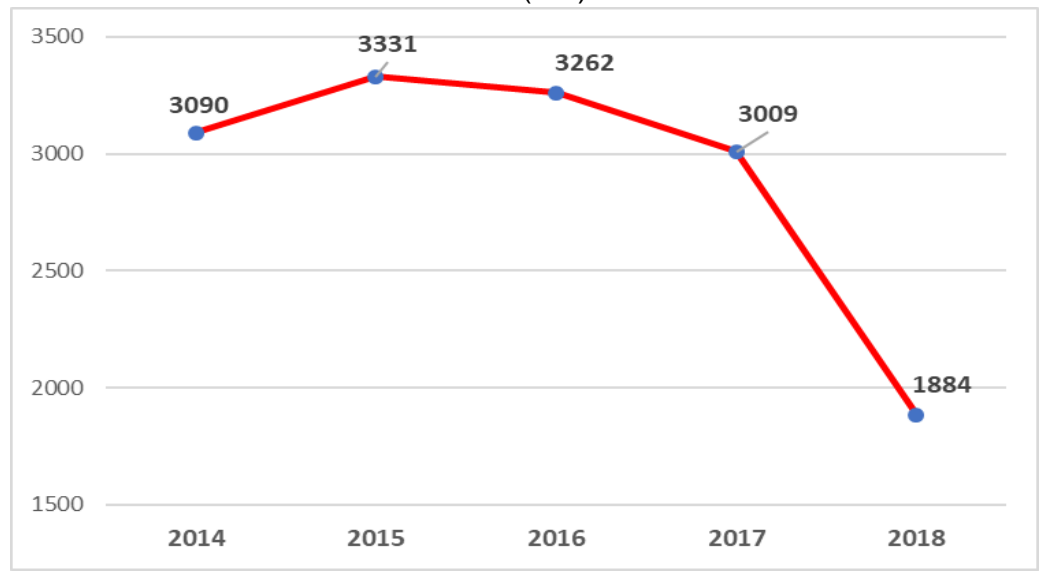

Fonte - SSP, 2018. 
Yata Anderson Gonzaga Masullo Janderson Rocha Silva

Esse percentual de concentração de CVNLI no sexo feminino, reflete-se na centralização das ocorrências em determinadas regiões da capital maranhense (Gráfico 6). Observa-se, que 5\% dos bairros de São Luís concentram $43,3 \%$ dos casos de CVNLI registrados no período analisado, enquanto que em 1\% dos bairros ocorrem 18,6\%. Entre 2014 e 2018, identifica-se reduzida variação de concentração e dispersão das ocorrências.

Gráfico 6 - Percentual de concentração de CVNLI em 5\% e 1\% dos bairros de São Luís (MA), entre 2014 e 2018.

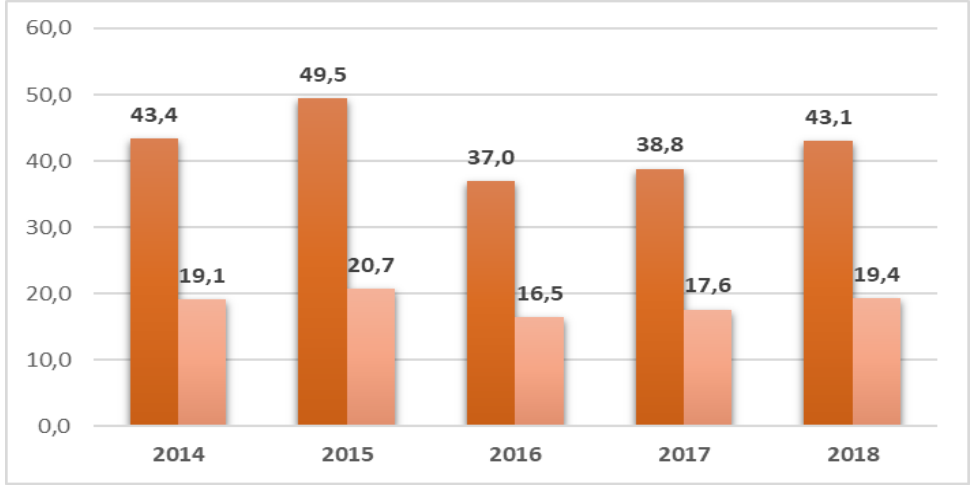

Fonte - SSP, 2018.

Especificamente, em relação à dinâmica espacial e temporal dos casos de CVNLI, com vítimas mulheres entre 2014 e 2018 em São Luís, identificam-se vetores de concentração, na faixa central do município e dispersão das ocorrências na área rural. Através do mapa da Figura 5, observa-se maior incidência dos crimes violentos não letais com vítimas mulheres na região central do município (Centro, Desterro, Filipinho e Monte Castelo), bem como em bairros na área limítrofes a São José de Ribamar (Cohatrac e Forquilha). Ao mesmo tempo, ressalta-se a redução da incidência dos registros na área Itaqui-Bacanga e a ampliação em bairros considerados de classe média-alta, localizados em regiões turísticas, como Ponta D' areia, Calhau e bairros circunvizinhos.

Figura 5 - Mapa dos casos de CVNLI em mulheres entre 2014 a 2017, São Luís/MA.

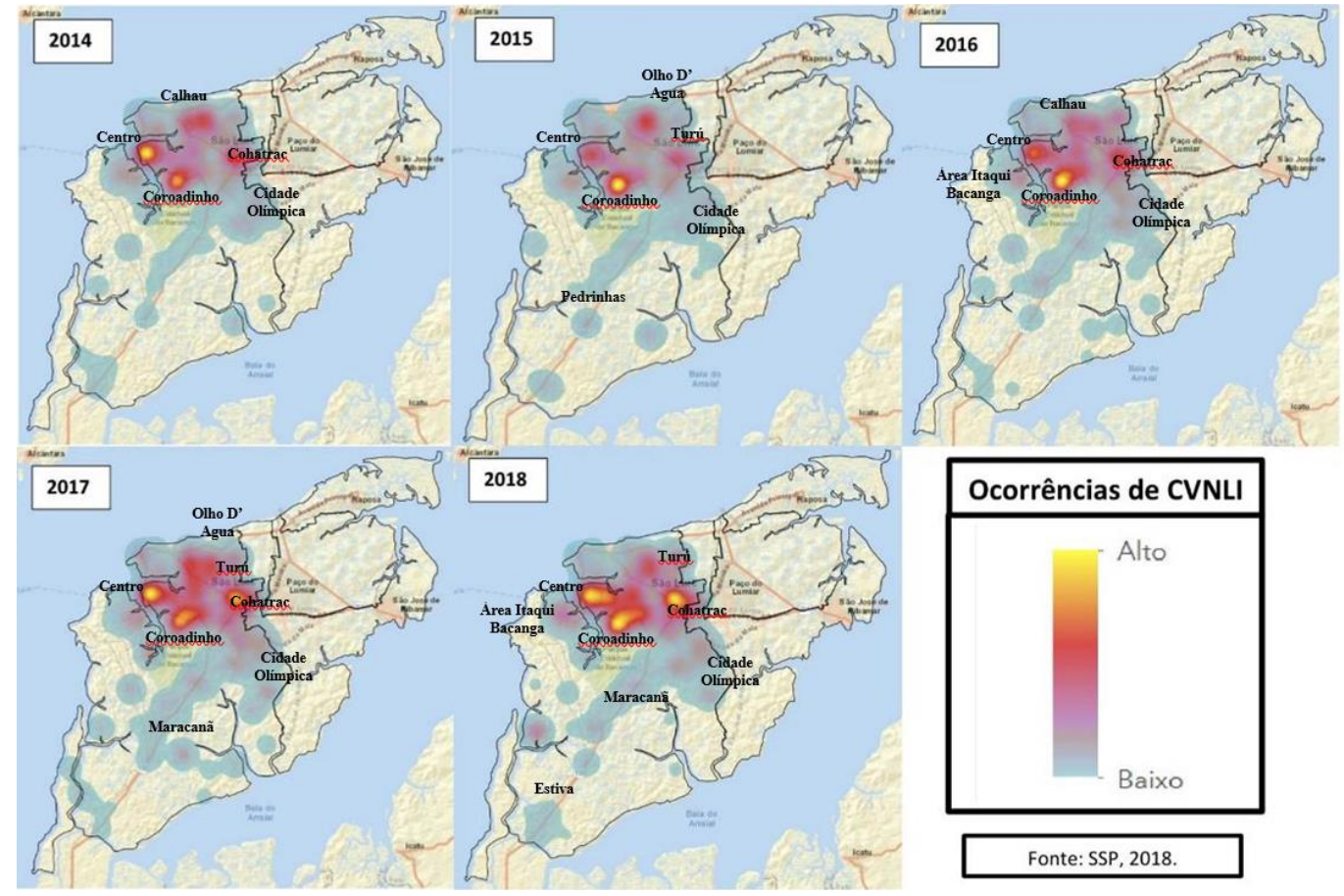


Identifica-se, consolidação da redução das ocorrências de CVNLI, em grande parte do município. Mesmo com uma série histórica reduzida, observa-se que permanece a concentração destes crimes na área urbana. Contudo, nota-se migração dos casos para localidades, que anteriormente possuíam poucos registros ou mesmo onde estes não existiam. Notadamente, esse fluxo transcorre em direção aos bairros localizados na zona rural do município. Essas localidades, possuem características marcantes, como difícil acesso, baixos indicadores socioeconômicos e infraestrutura precária, bem como crescente contingente populacional registrado nos últimos anos, como resultado da migração impulsionada por instalação de empreendimentos federais e estaduais. Destaca-se o programa Minha Casa Minha Vida.

No entanto, faz-se necessário ressaltar, o grande percentual de subnotificação quando se analisam os casos de CVNLI. Isso, ocorre principalmente com mulheres de classe média-alta, por diversos motivos, como vergonha de expor a família, dependência emocional e econômica ou medo (SILVA, 2007).

Entre as ocorrências de CVNLI, Ceccato (2014) destaca o estupro. Segundo este autor, esse tipo de crime ocorre tanto em áreas centrais quanto periféricas da cidade, com características semelhantes. Como observa Andresen (2014), os crimes não letais, são os mais prováveis de ocorrer em regiões com intenso fluxo (comércio, shopping centers, bares, restaurantes, hospitais, parques e escolas), onde existe ou atraem uma alta convergência de possíveis infratores e vítimas.

Assim como Andresen et al. (2017), os resultados obtidos demonstram que os pontos de maior concentração de ocorrências são áreas com alvos mais "adequados", devido ao número de oportunidades produzidas em locais públicos. O aumento da interação entre vítimas e infratores, amplia a probabilidade das ocorrências. Entretanto, destaca-se que o percentual de subnotificação nos mostra a concentração das denúncias registradas, e não necessariamente as áreas onde existem o maior quantiativo de crimes sexuais.

$\mathrm{Na}$ capital maranhense, detecta-se a formação de diferentes clusters com os casos de CVNLI, registrando significativa dinâmica espaço-temporal. Isso, pode ser observado na formação de um conjunto de bairros, que caracterizam toda a região de estudo (Figura 6).

Figura 6 - Mapa de CVNLI com vítimas mulheres (LISA) entre 2014 a 2018, São Luís/MA.

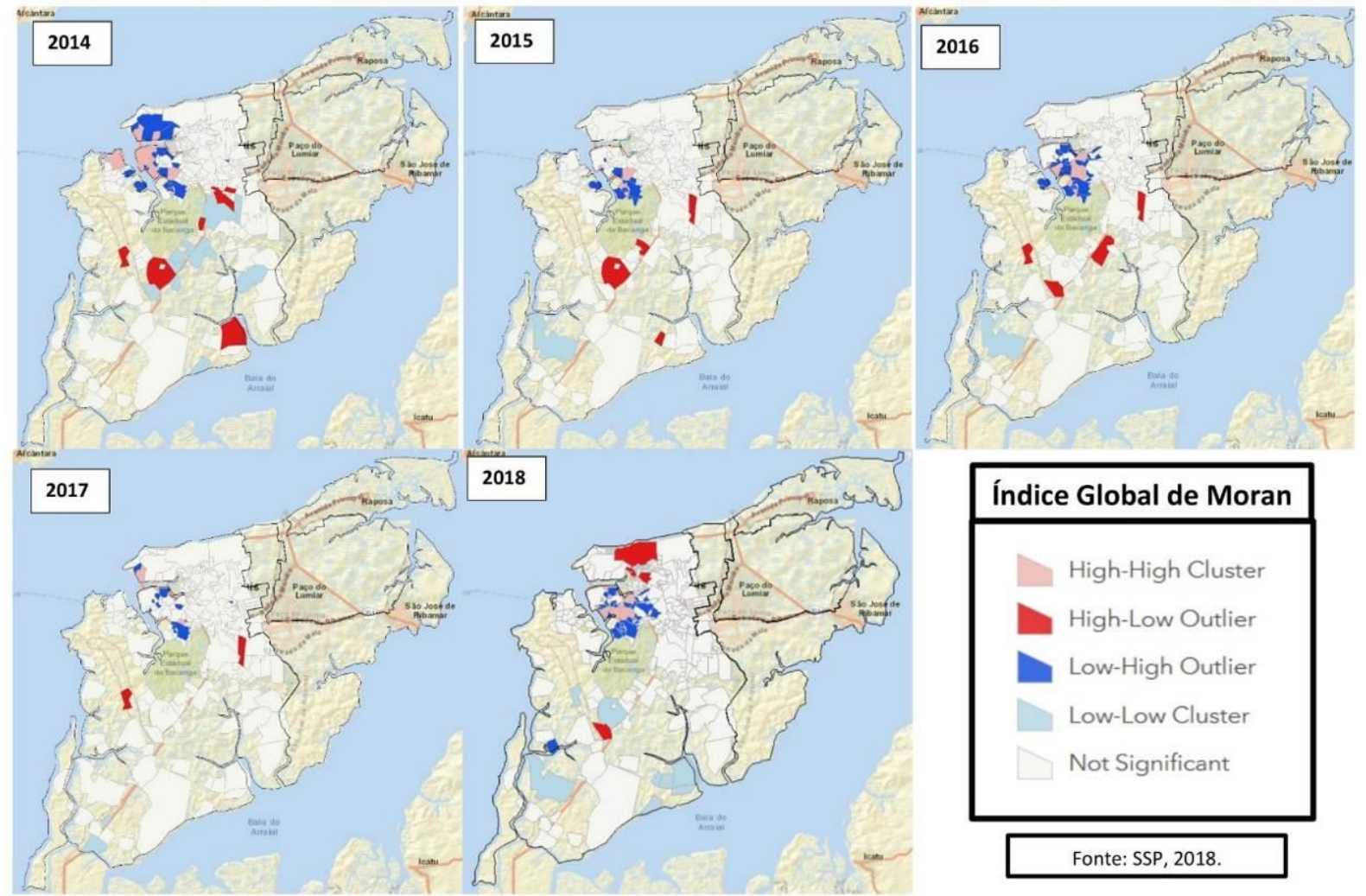


Em 2014, identifica-se clusters HH (alta concentração de casos) entre os bairros do Jaracaty, São Francisco, Centro, Areinha e Área Itaqui-Bacanga. Essa correlação, demonstra áreas com alta incidência, cercados de outros bairros com alta probabilidade de se registrar ocorrências de CVNLI. Ao mesmo tempo, identifica-se outliers HL (alta concentração de casos próximos a áreas com baixa incidência) na zona rural (Maracanã, Vila Maranhão e Quebra Pote) e na zona urbana (Jardim São Cristovão e São Bernardo), além de LH (baixa concentração de casos próximos a áreas com alta incidência) entre os bairros do Renascença, Liberdade, Coroadinho e Bairro de Fátima. Ressalta-se, a formação de clusters LL nos bairros ligados pela BR 135, como Tirirical, São Raimundo, Tibiri e Tibirizinho, demonstrando os vetores de dispersão das ocorrências.

No ano de 2015, amplia-se a concentração dos clusters, com a presença de outliers LH na região do polo Coroadinho e cluster HH no João Paulo, Parque dos Nobres e Pindorama. Identifica-se, de forma isolada bairros com alta proporção, cercados por bairros com baixa incidência de CVNLI com vítimas mulheres, formando clusters $\mathrm{HL}$ entre os bairros do Maracanã, Jardim São Cristovão e Vila Esperança. Em 2016, os outliers LH se espraiam interligando o Coroadinho, Bairro de Fátima, Liberdade e Camboa, enquanto o cluster $\mathrm{HH}$, se consolidam entre o João Paulo, Areinha e Alemanha.

No ano de 2017, identificam-se na zona rural clusters $\mathrm{HH}$, entre os bairros da Vila Colier e Tanandiba. $\mathrm{Na}$ zona urbana, observa-se a formação de clusters HH nos bairros do São Francisco e Camboa. Em 2018, a formação dos clusters HH, concentra-se entre a Alemanha, João Paulo, Monte Castelo e Bairro de Fátima, enquanto os outliers LH no Coroadinho, Liberdade e Anil. Ao mesmo tempo, identifica-se a formação e dispersão de clusters LL, na zona rural e urbana, além de outliers HL entre o Calhau e Vinhais.

Os dados apresentados, revelam um quadro grave, onde a violência psicológica, patrimonial, física ou sexual, demonstra uma tendência de agravamento crescente, muitas vezes antecedendo uma violência fatal, tendo em vista que, em muitos casos, as mulheres passam várias vezes pelo sistema de saúde, antes de chegarem a uma delegacia ou a um juizado, e muitos casos nunca chegam a denunciar (IPEA, 2017).

\section{CONSIDERAÇÕES}

Para além da análise dos fenômenos individualizadas, os resultados obtidos no presente estudo, demonstram com base em métodos estatísticos, regimes espaciais extremamente polarizados dentro do ambiente urbano. A partir destas técnicas, identificam-se agravos característicos das zonas de centralidade (médio-alto padrão) e das periferias (baixo padrão). Essa realidade, confirma-se quando se observa que, independentemente do tipo de crime registrado, os clusters $\mathrm{HH}$ se formam somente em áreas consideradas de baixo padrão. No entanto, visualiza-se que os outliers $\mathrm{HL}$, concentram-se tanto em áreas com menores indicadores socioeconômicos, quanto em áreas de classe média-alta.

É importante reconhecer, que as ocorrências de crimes violentos não letais em bairros com baixos indicadores na zona rural e urbana, evidenciam ainda os locais onde se obteve o maior número de denúncias registradas, e não necessariamente as áreas onde existem o maior quantiativo de crimes, considerando a significativa subnotificação. No entanto, percebe-se elevação dos registros em áreas de clase média-alta, o que apresenta um indicativo importante para se quebrar um barreira histórica de não reportar a violência sofrida para as autoridades, seja por vergonha ou por qualquer tipo de dependência.

Esse contexto, nos mostra que a dinâmica da violência se altera no tempo e no espaço. Isso demonstra fluidez, bem como expõe as disparidades socioeconômicas e desorganização social, como agravo e não como único elemento determinante para perpetuação ou proliferação dos crimes violentos letais e não letais.

O tratamento e processamento dos dados dos crimes violentos com vítimas mulheres, demonstraram como esses crimes são extremamente concentrados. Em São Luís, verifica-se que atualmente $5 \%$ dos bairros, concentram $43,1 \%$ das ocorrências de CVNLI e $83,3 \%$ de CVLI. Em relação à formação dos clusters de bairros com ocorrências de CVLI e CVNLI, observa-se que $80 \%$ dos bairros registram agrupamentos não significativos, o que comprova o alto grau de concentração dos casos, bem como apresenta sua natureza altamente fluida. Em parte, essa dinâmica se justifica pela influência das ações e políticas públicas desenvolvidas e implementadas a partir de 2015 pelo Governo do Estado. 
Por outro lado, Weisburd et al. (2015) coloca que, se o crime está tão concentrado em locais específicos da cidade, então o policiamento e outros recursos de prevenção ao crime, também devem ser concentrados. Isso, se aplica não apenas às intervenções na justiça criminal, mas também às intervenções sociais que possam melhorar os problemas da segurança pública.

Considerando os clusters identificados com alta prevalência das ocorrências de mulheres vítima de CVLI e CNVLI, deve-se refletir sobre o desenvolvimento e o redirecionamento de políticas públicas específicas, como a Carreta da Mulher e Ônibus Lilás. Essas ações estratégicas, possuem a finalidade de ampliar os canais de acesso a informação, de denúncias e principalmente de atendimento as mulheres vítimas de violência.

O enfrentamento à violência contra mulheres, portanto, deve se dar em diversas frentes, de forma sistemática e em todo o território, mas também com ações pontuais direcionadas às diferentes especificidades identificadas em um mesmo território. É necessário desenvolver políticas de prevenção e redução à violência contra mulheres, considerando não só a prevalência espacial das ocorrências, mas também os aspectos sociais e culturais que reforçam a naturalização de comportamentos violentos contra a mulher. Ressalta-se, também que a subnotificação é característica nesse tipo de violência, determinando que as ações de enfrentamento não se limitem a bairros que apresentem esses registros.

Por fim, reforçamos, que os resultados obtidos não apresentam informações determinísticas, mas sim probabilísticas. No entanto, constituem subsídios para a proposição de políticas públicas e estratégias de monitoramento, aperfeiçoamento de políticas públicas baseadas na realidade, padrões e evidências.

\section{REFERÊNCIAS}

ANDRESEN, M. A. et al. Age and the distance to crime. Criminology and Criminal Justice, 14(3). 2014.

https://doi.org/10.1177/1748895813494870

ANDRESEN, M. A. et al. The Trajectories of Crime at Places: Understanding the Patterns of Disaggregated Crime Types. Journal of Quantitative Criminology. 33(3). 2017. p. 427-449. https://doi.org/10.1007/s10940-016-9301-1

ANSELIN, L. Local Indicators of Spatial Association - LISA. In: Geographical Analysis, Vol. 27, No. 2. 1995.

https://doi.org/10.1111/j.1538-4632.1995.tb00338.x

ANSELIN, L., J. et al. Spatial analyses of crime. In Measurement and analysis of crime and justice. ed. D. Duffee, Washington, DC: National Institute of Justice. 213-62. 2000.

CÂMARA, G. et al. Análise espacial e geoprocessamento. In: DRUCK, S.; CARVALHO, M. S.; CÂMARA, G.; MONTEIRO, A. V. M. (eds). Análise Espacial de Dados Geográficos. Brasília: EMBRAPA, 2004.

CECCATO, V. The nature of rape places. Journal of Environmental Psychology, 40, 97-107. 2014 https://doi.org/10.1016/.j.jenvp.2014.05.006

CECCATO, V., et al. Women's mobility and the situational conditions of rape: Cases reported to hospitals. Journal of Interpersonal 2017. https://doi.org/10.1177/0886260517699950

CERQUEIRA, D. et al. Indicadores multidimensionais de educação e homicídios nos territórios focalizados pelo pacto nacional pela redução de homicídios. Brasília: Ipea, 2016.

CERQUEIRA, D. COELHO D. S. C. Estupro no Brasil: uma radiografia segundo os dados da Saúde. Nota Técnica. Instituto de Pesquisa Econômica Aplicada - IPEA. 2014. 30p. 
CHAINEY, S. P.; MONTEIRO, J. The dispersion of crime concentration during a period of crime increase. Security Journal. v. 1. 2019. p. 1-18.

CRISP - Centro de Estudos de Criminalidade e Segurança Pública. Pesquisa Nacional de Vitimização. Sumário Executivo SENASP. DATAFOLHA/CRISP/UFMG. 2013. 43p.

FERREIRA, M. C. Iniciação à análise geoespacial: teoria, técnicas e exemplos para o geoprocessamento. Editora UNESP. São Paulo. 2014. 343p.

HAGERTRAND, T. Aspects of the spatial structure of social communication and diffusion of information. Papers of the Regional Science Association. Chicago. Chicago University Press. 16. 1966.

p.

27-42.

https://doi.org/10.1007/BF01888934

HEWITT, A. N. et al. Identifying the nature of risky places for sexual crime: The applicability of crime pattern and social disorganization theories in a Canadian context. Journal of Criminal Justice. 57.

$2018 . \quad$ p. 35

56.

https://doi.org/10.1016/i.jcrimjus.2018.03.003

IBGE. Censo Demográfico 2000/2010 - População residente por cor ou raça, sexo, situação do domicílio e grupos de idade. Disponível em: http://www2.sidra.ibge.gov.br/bda/tabela/listabl.asp?z=cd\&o=2\&i=P\&c=2093. Acesso em: 14 de dezembro de 2016.

Censo 2010 aprimorou a identificação dos aglomerados subnormais. Rio de Janeiro, 2011 (a). Disponível em: <http://www.ibge.gov.br /home/presidencia/noticias/ noticia_visualiza. php?id_noticia=2051. Acesso: em 01 abr. 2012.

IMESC, Instituto Maranhense de Estudos Socioeconômicos e Cartográficos. Relatório: Dinâmica Espacial dos Crimes Violentos no município de São Luís. IMESC. 2018. 52p.

Crimes violentos contra mulheres no Maranhão. Instituto Maranhense de Estudos Socioeconômicos e Cartográficos-IMESC. v.2, n.1. São Luís. IMESC, 2020. 19p.

IPEA - Instituto Pesquisa Econômica Aplicada. Nota técnica: Atlas da Violência 2016. IPEA/ FBSP Fórum Brasileiro de Segurança Pública. 2016.

. Atlas da Violência 2017. IPEA/ FBSP - Fórum Brasileiro de Segurança Pública. 2017.

Anuário Brasileiro de Segurança Pública 2019. IPEA. 2019. 205p.

Atlas da violência 2019. Organizadores: Instituto de Pesquisa Econômica Aplicada; Fórum Brasileiro de Segurança Pública. Brasília: Rio de Janeiro. Instituto de Pesquisa Econômica Aplicada; Fórum Brasileiro de Segurança Pública. 2019. 115p.

JONES, R. W. PRIDEMORE. W. A. Toward an Integrated Multilevel Theory of Crime at Place: Routine Activities, Social Disorganization, and The Law of Crime Concentration. Journal of $\begin{array}{llllll}\text { Quantitative Criminology } \quad 3 & 35 & \text { (3). } & 2019 . & \text { p. } & \text { 534-572. }\end{array}$ https://doi.org/10.1007/s10940-018-9397-6

LEFEBVRE, H. A cidade do capital. Rio de Janeiro: DP e A editora, 1999. 112p.

LENTZ, J. Spatial Autocorrelation Statistics. 2009. Disponível em: <http://jenniferalentz.info/Teaching/StudyGuides/SpatialAutocorrelation.pdf>. Acesso em: 30 Dez. 2016. 
LIRA, P. S. Geografia do Crime e arquitetura do medo: uma análise dialética da criminalidade violenta e das instâncias urbanas. Editora Oficina LTDA. Vitória, ES. 2014.

MASULLO, Y. A. G. et al. Dinâmica espacial dos crimes violentos em mulheres no município de São Luís, MA. In: SIMPÓSIO NACIONAL DE GEOGRAFIA DA SAÚDE, 9., 2019, Blumenau - SC.

MELO, E. C.; MATHIAS, T. A. F. de. Distribuição e autocorrelação espacial de indicadores da saúde da mulher e da criança, no Estado do Paraná. Brasil. Rev. Latino-Am. Enfermagem, v.18, n. 6. 2010. p. $1-10$.

MELO, S. N.; MATIAS, L. F.; ANDRESEN, M. A. Crime concentrations and similarities in spatial crime patterns in a Brazilian context. Applied Geography, v. 62, p. 314-324, 2015. https://doi.org/10.1016/i.apgeog.2015.05.012

MELO, S. N.; BEAUREGARD, E.; ANDRESEN, M. A. Factors related to rape reporting behavior in Brazil: Examining the role of spatio-temporal factors. Journal of interpersonal violence, v. 34, n. 10, p. 2013-2033,

2019.

https://doi.org/10.1177/0886260516658758

MELO, S. N. ; ROCHA, J.; MASULLO, Y. A. G. Análise longitudinal dos fatores associados a epidemia/endemia de homicídios nas capitais brasileiras. CONFINS (PARIS). No 42. 2019. https://doi.org/10.4000/confins.22818

MELO, S. N.; BOIVIN, R.; MORSELLI, C. Spatial dark figures of rapes:(In) Consistencies across police and hospital data. Journal of Environmental Psychology, v. 68, p. 101393, 2020. https://doi.org/10.1016/j.jenvp.2020.101393

MONITOR DE VIOLÊNCIA. 2019. Disponível em: http://especiais.g1.globo.com/monitor-daviolencia/2018/mortes-violentas-no-brasil/. Acesso: em 01 dez. 2019.

MUSTAINE, E. E. et al. Differentiating single and multiple victim child sexual abuse cases: A research note considering social disorganization theory. Journal of Child Sexual Abuse. 23(1). 2014. p. 38-54. https://doi.org/10.1080/10538712.2014.863260

RAFFESTIN, C. Por uma Geografia do Poder. Tradução: Maria Cecília França. Ática, São Paulo. 1993. 269p.

ROGERSON, P. A. Métodos estatísticos para a geografia: um guia para o estudante. Tradução técnica: CARVALHO; Paulo Braga; RIGOTTI, José Irineu Rangel. BOOKMAN. $3^{\circ} E D$. Porto Alegre. 2012.

ROSA, E. M. Lesão corporal circunstanciada pela violência doméstica. 2014. Disponível em:https://emanuelmotta.jusbrasil.com.br/artigos/135520622/lesao-corporal-circunstanciada-pelaviolencia-domestica. Acesso em: 14 de novembro de 2017.

SAFFIOTI, H. Gênero, Patriarcado e Violência. Expressão Popular. 2015. 158p.

SANTOS, M. A. Natureza do Espaço: técnica, razão e emoção. 4. ed. São Paulo: Editora da Universidade de São Paulo, 2004.

SILVA, B. G. R. S da. A Violência conjugal contra mulheres das classes médias do município de São Paulo. Dissertação de Mestrado. Universidade de São Paulo. Programa de Pós-Graduação em Sociologia. 2007. 123p.

SSP - SECRETARIA DE ESTADO DE SEGURANÇA PÚBLICA. Banco de dados. Disponível em: https://www.ssp.ma.gov.br/. Acesso: 31 dez. 2018. 
Yata Anderson Gonzaga Masullo

Janderson Rocha Silva

UNICEF. United Nations Children's Fund. A Familiar Face: Violence in the lives of children and adolescents. UNICEF. 2017. 215p.

WEISBURD D, et al. The criminology of place: street segments and our understanding of the crime problem. Oxford University Press, New 2012. https://doi.org/10.1093/acprof:oso/9780195369083.001.0001

Understanding and controlling hot spots of crime: The importance of formal and informal social controls. Prevention Science 15. 2015. p. 31-43. https://doi.org/10.1007/s11121-012-0351-9

Recebido em: 16/01/2020

Aceito para publicação em: 15/07/2020 